https://doi.org/10.31977/grirfi.v21i3.2457

Recebido: 30/06/2021 | Aprovado: 30/09/2021

Received: 06/30/2021 | Approved: 09/30/2021

\title{
ÉTICA E SOLIDARIEDADE: UMA LIÇÃO DA PANDEMIA
}

\author{
Alvino Moser ${ }^{1}$ \\ Centro Universitário Internacional (UNINTER) \\ D) https://orcid.org/0000-0001-7828-5067 \\ E-mail:moseral.am@gmail.com \\ José Lauro $^{2}$ \\ Universidade Federal do Tocantins (UFT) \\ (D) https://orcid.org/0000-0001-7817-8165 \\ E-mail: jlauro@mail.uft.edu.br \\ Juliana Santana ${ }^{3}$ \\ Universidade Federal do Tocantins (UFT) \\ (iD) https://orcid.org/0000-0001-8192-1255 \\ E-mail: jusantanaa@hotmail.com
}

\section{RESUMO:}

O artigo examina uma possível ética para o cenário atual, a fim de aproximar os seres humanos e despertar neles um sentimento de solidariedade. Para tal exame, a princípio, questiona teorias como o utilitarismo revisto por Rawls. Busca um critério válido para todos os participantes de um certo universalismo ou para um "nós" real e não excludente. Propõe o apelo à solidariedade como uma forma de unir as pessoas, oposta ao egoísmo. Depois, defende a solidariedade, conforme Richard Rorty. Este filósofo afirma a necessidade de um acordo entre os membros da sociedade, pois só assim haveria um verdadeiro "nós". A seguir, observa a questão de como tornar as pessoas mais solidárias, mas sem recorrer à perspectiva metafísica tradicional acerca da humanidade: aposta na existência de características partilhadas que levam à igualdade democrática, porém respeitando as diferenças de cada um. Questiona ainda o que levaria os mais ricos a se solidarizarem com os mais pobres, observando propostas feitas por Rorty acerca da sensibilização, da apresentação do risco de pobreza aos ricos e de um apelo ao sentimento de humanidade. Por fim, considera o igualitarismo rortyano, segundo o qual a solidariedade está além da racionalidade. Ela seria historicamente constituída e embasada na relação com o outro, no sentimento comum de vulnerabilidade, crucial à sociedade em tempos de pandemia.

PALAVRAS-CHAVE: Solidariedade; Ética; Pandemia; Humanidade.

\section{ETHICS AND SOLIDARITY: A PANDEMIC LESSON}

\begin{abstract}
:
The paper examines a possible ethics for the current scenario, in order to bring human beings closer together and awaken in them a feeling of solidarity. For such an examination, at first, theories such as the utilitarianism reviewed by Rawls are questioned. It searches for a valid criterion for all participants of a certain universalism or for a real and non-exclusive "us". The call for solidarity is proposed as a way of uniting people, as opposed to selfishness. Then solidarity is defended, according to Richard Rorty. This philosopher affirms the need for an agreement among the members of society, because only then would there be a real "we". Next, there is the question about how to make people more supportive, but without resorting to the traditional metaphysical perspective on humanity: there is a bet on the existence of shared characteristics that lead to democratic equality, however, respecting the differences of each one. It is still questioned what would lead the richest to sympathize with the poorest, observing the proposals made by Rorty about raising awareness, presenting the risk of poverty to the rich and appealing to the feeling of humanity. Finally, Rortyan egalitarianism is considered, according to which solidarity is beyond rationality. It would be historically constituted and based on the relationship with the other, on the common feeling of vulnerability, crucial to society in times of pandemic.
\end{abstract}

KEYWORDS: Solidarity; Ethics; Pandemic; Humanity.

${ }^{1}$ Doutor(a) em Ética pela Université Catholique de Louvain (UCL), Louvain, Bélgica. Decano(a) do Centro Universitário Internacional (UNINTER), Curitiba - PR, Brasil.

2 Doutor(a) em Ciência da Educação pela Universidade do Minho (UMinho), Braga, Portugal. Professor(a) da Universidade Federal do Tocantins (UFT), Palmas - TO, Brasil.

${ }^{3}$ Doutor(a) em Ética e Filosofia Política pela Universidade Federal de Santa Cantarina (UFSC), Florianópolis - SC, Brasil. Professor(a) da Universidade Federal do Tocantins (UFT), Palmas - TO, Brasil.

MOSER, Alvino; LAURO, José; SANTANA, Juliana. Ética e solidariedade: uma lição da pandemia. Griot : Revista de Filosofia, Amargosa-BA, v.21 n.3, p.283-297, outubro, 2021. 


\section{Introdução}

A situação de pandemia pela qual passamos põe em foco nossa relação com o outro. Tal relação deveria ser de reciprocidade, mas o que percebemos como regente das condutas humanas em nosso tempo é uma espécie de utilitarismo egocêntrico. Todavia, propor uma máxima que permita um cálculo pautado no máximo de felicidade, prazer ou utilidade que as ações pudessem proporcionar ao maior número de pessoas possível ou a um indivíduo não parece um guia viável para as ações em sociedade. A negativa desse tipo de proposição ética acontece porque entendemos que o ser humano não é somente razão, mas está sujeito à contingência e às paixões, aos instintos e aos desejos.

Frente a isso, surge a questão: qual ética poderia ser válida num cenário como o de hoje, a fim de aproximar e despertar um sentimento de solidariedade entre os seres humanos? Para a resposta, $o$ artigo terá como aliadas as teorias de Richard Rorty acerca da solidariedade ${ }^{4}$.

Num primeiro momento, questionamos o utilitarismo revisto por Rawls (1981), bem como o imperativo categórico kantiano e outras formulações éticas, tendo em vista sua pertinência num cenário como o atual. Com isso iniciamos uma busca por um critério válido para todos os participantes de um certo universalismo, ou para um "nós" que não seja excludente. Para isso, propomos o apelo à solidariedade, que seria uma forma de unir as pessoas e que se oporia ao egoísmo. A proposta é pautada na reciprocidade, em uma união fraterna entre os seres humanos, associados, entre outros motivos, por interesses comuns, mas especialmente por vulnerabilidades.

Em um segundo momento, a fim de defender a observação a respeito da solidariedade, recorremos a teorias elaboradas por Rorty acerca desse assunto. $O$ filósofo afirma a necessidade de um acordo entre os membros da sociedade, pois só assim haveria um verdadeiro "nós". Educar conjuntamente a razão e os centros hedonísticos do cérebro possibilitaria a associação humana em uma sociedade na qual estaria resolvida a questão da ambiguidade do "nós".

Num terceiro momento, são feitas reflexões sobre a necessidade ética da solidariedade. A questão de como tornar os humanos mais solidários é abordada, mas sem a perspectiva metafísica tradicional sobre a natureza da humanidade. De outro modo, Rorty aponta uma universalidade pautada em características partilhadas por todos, levando-os a serem tratados com igualdade democrática, mas com respeito às diferenças de cada um.

Na sequência, num quarto momento, questionamos o que poderia levar os mais ricos a se solidarizarem com os mais pobres. A reflexão segue com a apresentação de três indicações feitas por Rorty para que isso seja viável: primeiro, a consolidação da sensibilização; depois, a apresentação do risco de pobreza aos ricos; por fim, a recomendação de um apelo ao sentimento de humanidade.

No último momento, consideramos o igualitarismo rortyano. A ação moral é, portanto, apresentada como uma intenção do "nós" defendido pelo filósofo. Propomos, então, a solidariedade como algo além da racionalidade, mas que se associa a um sentimento historicamente constituído e embasado na relação com o outro, que permite vê-lo como um dos nossos. Essa teoria extrapola a tradicional aposta na apreensão de uma humanidade explicada por meios metafísicos; diferentemente, é baseada no sentimento comum em relação à humilhação, na possiblidade da dor, ou seja, na percepção da vulnerabilidade presente em todos.

\footnotetext{
4 Neste artigo não se consideraram as posturas dos transcendentalismos e do empirismo como proposto por Edward Osborne Wilson no capítulo 11, "Religião e Ética", da obra A Unidade do Conhecimento- Consiliência.
} 


\section{A pandemia}

A crise sem precedentes que a humanidade enfrenta requer uma solidariedade global sem precedentes. Exige uma resposta de emergência. Mas também deve nos encorajar a lançar as bases para um mundo mais unido e mais resiliente diante dos desafios, que terá que ir além dos antigos equilíbrios para envolver mais os grandes players emergentes: China, mas também Índia e Rússia, América Latina e África ${ }^{5}$.

$O$ risco de um indivíduo de ficar doente depende, de maneira incerta, dos passos dados pela comunidade e do ambiente e das condições em que o indivíduo vive. Na verdade, a experiência humana com doenças infecciosas há muito deixou clara a importância da ação coletiva na preservação e proteção da saúde das populações (PARMET, 2008, p. 11).

Nas pandemias, como nas doenças, há sempre a relação entre o doente e o outro, seja como transmissor do vírus ou bactéria, seja como possível receptor. Os infectados se encontram com outros no mundo circundante. Estabelece-se, então uma relação de responsabilidade que nos impele a lembrar o célebre dito de Terêncio (Heautontimorumenos, v. 77 s., tradução nossa): Homo sum: humani nihil a me alienum puto. Vel me monere hoc vel percontari puta: Rectum'st, ego ut faciam ; non est, te ut deterream ("Eu sou um humano, nada do que é humano me é estranho. Por exemplo, mesmo que eu tenha que admoestar ou que eu tenha que perguntar a alguém: É correto (ou é certo), que eu o faça; pois, não existe quem poderia detê-lo"). As frases de Terêncio nos vêm à memória porque as pessoas têm liberdade de decidir, apesar das admoestações.

Santo Agostinho (2007) afirma que quando isto foi dito para traduzir esse sentimento, o teatro ressoou em aplausos; e merecidamente, de fato, pois o texto está repleto da própria essência da benevolência com todos os outros e desconsideração de si mesmo. $O$ impacto das palavras de Terêncio é tamanho que Cícero cita a passagem em sua obra De Officiis, B. i., C. 9; impacto esse comprovado pela presença do dito também em obras mais recentes que a do orador romano. As observações de Sir Richard Steele sobre esta passagem, no Spectator, $\mathbf{n}^{\circ}$ 502, são dignas de serem transcritas extensamente:

A peça era o Autocomentador. É do princípio ao fim uma imagem perfeita da vida humana, mas não observei em toda a passagem algo que pudesse provocar risadas. Quão bemdisposto deve ser aquele povo, que poderia ser entretido com satisfação por tão sóbrio e educado Mirth? Na primeira Cena da Comédia, quando um dos velhos acusa o outro de Impertinência por se intrometer em seus negócios, ele responde: 'Eu sou um homem e tudo o que é humano me é alheio, logo não posso ajudar sentindo qualquer tristeza ao que possa acontecer ao homem. ' Diz-se que esta frase foi recebida com um aplauso universal. Não pode haver maior argumento da boa compreensão geral de um povo do que o seu súbito consentimento em dar sua aprovação a um sentimento que não contém emoção. Se fosse falado com sempre tão grande habilidade do ator, a maneira de proferir aquela frase não poderia ter nada nela que pudesse atingir qualquer pessoa, exceto as pessoas da maior humanidade - ou melhor, pessoas elegantes e hábeis na observação sobre isso. É possível que ele possa ter colocado a mão no coração e, com uma insinuação vitoriosa no semblante, expressou ao vizinho que era um homem que defendia sua própria causa (STEELE, 1891, tradução nossa).

Por este pressuposto há obrigação mútua entre indivíduos partilhada para que haja cooperação entre todo e cada um dos membros da comunidade, obrigação extensiva às mesmas

\footnotetext{
${ }^{5}$ Sobre esse assunto, conferir a matéria sobre a necessidade de uma solidariedade mundial frente à crise provocada pelo Covid-19 publicada no Le monde de 14 de abril de 2020.
} 
comunidades. O que implica inovações políticas, pois os formuladores de políticas precisam reconhecer que operam de maneira complexa e dinâmica em ambientes incertos. Os governos das potências mais fortes orientam-se por uma ética extremamente utilitarista e devastadora. Sobretudo quando lidam com os desafios globais impostos, por exemplo, por cataclismos globais e pandemias.

As regras de reciprocidade e a situação dos mais fracos ou impotentes são relegadas a um segundo plano, quando não são simplesmente ignoradas. Países têm e tiveram acesso a insumos necessários e imprescindíveis em detrimento de outros que não têm e não tiveram a que ou a quem recorrer. Emerge assim um sério impasse ético nas relações sociais. John Rawls, em Teoria da Justiça (1981), numa perspectiva utilitarista, procurou suprir o gap deixado com a decadência das teorias anteriores, como a marxista, para regular as relações entre as nações. A "ética", se é que pode ser denominada assim, que irrompe de maneira arrasadora e avassaladora, é a ética utilitarista egocêntrica, mostrando que o que vale é a lei do mais forte: se não pelo argumento da força física, mas pela força econômica a sobrepujar as considerações racionais. E, sobretudo, as considerações humanistas e humanitárias.

Embora John Rawls pretenda corrigir o utilitarismo, não se deve olvidar que a máxima dessa filosofia é: Uma ação é boa na medida em que possa produzir o maior benefício para o maior número de pessoas. Mas, quem fará esse cálculo ideal? Nas decisões das pessoas há motivos conscientes e inconscientes. E estes dependem em grande parte dos centros hedonísticos do cérebro. Não se tem o controle sobre esses centros, entre os quais há os instintos, as paixões e as pulsões. Não há dominação total e consciente sobre esses centros, como já o dissera o poeta Ovídio (Metamorfoses, VII, 20, tradução nossa) no célebre verso: Video meliora proboque, sed deteriora sequor ("Eu vejo as coisas melhores, mas sigo as piores.").

Nem todos aceitam que, embora não seja o livre juízo a iniciar uma ação voluntária, ele, de todo modo, controla sua execução. Em outras palavras, se a intenção de agir está fora do controle consciente, sua transformação em ato motor é influenciada pelo controle consciente.

Portanto, a hipótese aventada por Rawls de que os que legislam devem decidir num "véu de ignorância" é utópica e dificilmente realizável por todos e cada um dos membros da sociedade (RAWLS, 1981). A crítica que endereçamos ao utilitarismo também atinge o imperativo categórico de Kant $(2005)^{6}$, e a intuição do bem e do mal que seria inata na consciência humana. Como aceitar que um decida por todos? Isso seria impossível, a menos que se aceite o absolutismo de Hobbes (2003). Parece-nos necessário buscar outro critério que atenda a todos de um certo universo, ou ao menos a um "nós" determinado e não exclusivo.

Pode-se então apelar ao sentimento de solidariedade. Mas, o que é a solidariedade? É o que une as pessoas para ajuda mútua. Pela solidariedade as pessoas se sentem unidas, seja porque fazem parte da mesma família, seja porque moram na mesma cidade, no mesmo país, no mesmo planeta. É a oposição tanto ao egoísmo como ao egocentrismo. Exige o combate às injustiças, a ajuda mútua. Em sua etimologia, a palavra vem do latim solidus, que significa inteiro, consistente, aquilo que vincula entre si os devedores de uma soma. Então, solidariedade é o sentimento de responsabilidade e dependência recíproca dentro de um grupo de pessoas que são moralmente obrigadas umas às outras. Por conseguinte, os problemas encontrados por um ou

\footnotetext{
${ }^{6}$ A Fundamentação da metafísica dos costumes inicia com a proposição: "A boa vontade é o que está mais partilhado entre os homens", e a boa vontade consiste em querer cumprir o dever pelo dever. Citando: Neste mundo, e até também fora dele, nada é possível pensar que possa ser considerado como bom sem limitação a não ser uma só coisa: uma boa vontade. Discernimento, argúcia de espírito [...], capacidade de julgar e como quer que possam chamar-se os demais talentos do espírito, ou ainda coragem, decisão, constância de propósito, como qualidades do temperamento, são sem dúvida, sob múltiplos respeitos, coisas boas e apetecíveis; podem entanto estes dons da natureza tornar-se extremamente maus e prejudiciais, se não for boa vontade que deles deve servir-se e cuja especial disposição se denomina caráter" (KANT, 2013, p. 21).
} 
mais de seus membros dizem respeito a todo o grupo. A solidariedade leva as pessoas a se comportarem como se estivessem diretamente confrontadas com o problema dos outros; caso contrário, o futuro do grupo (e, portanto, o seu próprio) poderia ser comprometido.

A solidariedade humana é um vínculo fraterno e um importante valor social a juntar o destino de todos os homens. É uma abordagem humanista que torna as pessoas conscientes de que todos os homens pertencem à mesma comunidade de interesses. Distingue-se do altruísmo, que leva a ajudar os outros pelo simples empenho moral, sem necessidade de reciprocidade, bem como da cooperação, em que todos trabalham com espírito de interesse geral para todos.

\section{A perspectiva de Richard Rorty}

A Sociedade 5.0 tem como escopo o bem-estar, o conforto, a saúde para todos, a inclusão de todos nos bens da sociedade comum. Contudo, esta sociedade inclui diversidade de membros, robôs e objetos criados por IA. Os seres artificiais não são apenas "ferramentas" a serem usadas pelos humanos, mas podem ser verdadeiros participantes não humanos da sociedade, como os animais, tanto os de estimação como os que servem aos indivíduos humanos (GLADDEN, 2019).

Não é, porém, a esta diversidade que nos referimos, mas à diferença de poder ser incluído nas futuras comunidades 5.0, pois tal inclusão exige elevados recursos financeiros e, não menos importante, conhecimentos de IA, IoT, Robótica e manipulação de aplicativos ou plataformas em constante inovação. Faz-se necessário flexibilidade e adaptabilidade, frutos de uma educação disruptiva e inovante, inclusive emergente.

Acresce a esta diversidade o modo como os privilegiados consideram que tratam os menos favorecidos, o que nos induz a considerarmos a solidariedade, tema este sobre o qual se debruçou Richard Rorty em obras como Who Are We?: Moral Universalism and Economic Triage, de 1996. Será que os ricos estão dispostos a ajudar os filhos dos outros de modo equitativo?

O que podemos denunciar é "a pirataria econômica" pela qual os ricos ficam sempre mais ricos, como verificamos durante a pandemia do Covid-19 que assola o mundo, por mais que o "liberal" Stephen Pinker (2018) queira provar o contrário, manipulando dados e fazendo leitura segundo seu ponto de vista para justificar que a condição dos mais pobres melhorou no geral, esquecendo-se de olhar para a imensa desigualdade dos habitantes do Riquestão.

Para Rorty, é preciso que haja acordo entre todos os membros da sociedade para constituir um verdadeiro nós. $\mathrm{E}$ a boa convivência dos cidadãos na pólis exige a observação de princípios éticos, pois, segundo Aristóteles, a ética supõe a política, dado que a ética é guia para ser bom cidadão (Ética a Nicômaco, I). Mas, qual é a ética dominante na atualidade? Estamos diante de uma valsa de éticas causada pela perda de paradigma, seja na teoria, seja na prática, causada pela substituição da ética pela tecnociência e pelas tecnologias. A ética impõe limites ao poder e ao querer e sua força reside na decisão autônoma das pessoas. Não se pode coagir os indivíduos ao dever, porque todos e cada um devem se autoimpor as obrigações.

O que dá suporte na atualidade, neste mundo que está se digitalizando, são os ditames da tecnociência, das tecnologias, dos aplicativos e das plataformas, em que somos dominados ou teleguiados pelos algoritmos (SUMPTER, 2019). É preciso ter força de vontade para dizer não a esses impulsos, sendo certos impulsos subliminares para agir de modo ético que impõem limites aos poderes emergentes das tecnologias em constante inovação.

As decisões não dependem apenas nem sobretudo da razão, mas da vontade, que sofre a influência dos centros hedonísticos do cérebro, dos instintos e das paixões. E, parece-nos, não há lugar nos currículos ou na educação para "educar a vontade". Os educadores, tanto os pais como 
os docentes, esbarram no que entendem por liberdade e autonomia. Perguntamo-nos na ânsia de ensinar os discentes, se não esquecemos de formar a vontade e o caráter?

Para Rorty não podemos visar à perfeição moral, mas podemos procurar levar em conta as necessidades dos outros mais do que o temos feito até agora (RORTY, 1996, p. 119). Devemos alargar o "nós", para nele incluir ricos, pobres, os que estão no poder, ou sem o poder; ocidentais ou orientais, e assim por diante. Frente a tal ambiguidade, é preciso saber em que contexto ou circunstância se fala do "nós". Não há um "nós" epistêmico, universal e objetivo. Há muitos "nós". Às vezes podemos ser tentados a pensar que o 'nós' são apenas aqueles que concordam conosco, mas isto seria agir para um "nós" exclusivo e excludente, segundo nosso ponto de vista.

Para os pragmatistas, como Rorty, as expressões "nós pragmatistas" ou "nós liberais burgueses pós-modernos" não são expressões que sejam estranhas, como o "nós modernos" de Nietzsche (RORTY, 1996, p. 122). Portanto, agir moralmente consiste, segundo esta perspectiva, em procurar sempre ampliar o "nós" para incluir sempre mais pessoas.

\section{Universalismo moral em época de globalização}

Não se pode esquecer que Rorty se diz ironista liberal, o que significa que aceita pôr em discussão suas crenças e opiniões, sendo esta a postura que caracteriza este ironismo; e que não aceita que se cause dor ou humilhação a um ser humano, sendo este um traço peculiar a um liberal. Portanto, ele abomina a crueldade (RORTY, 1989, p. 15). Mas, se atentarmos às suas afirmações em relação ao universalismo moral, o filósofo mostra-se pragmatista e afirma que os cidadãos privilegiados ou aqueles que estão em condição devem auxiliar os diferentes ou praticar a solidariedade.

Para expor a ética de Rorty, sobretudo nas relações humanas, consideramos o que ele entende por solidariedade. Expõe ele, em primeiro lugar, a perspectiva cristã segundo a qual somos solidários uns para com os outros porque somos todos filhos de Deus e irmãos em Cristo. Segue-se a perspectiva de Kant, para quem as obrigações para com os outros são nosso dever moral decorrente da boa vontade que existe em todos os homens, seres racionais.

\footnotetext{
Não desejo diminuir de forma alguma a força desses argumentos (de universalismo cristão e kantiano), mas somente arrancá-lo do que se considerou muitas vezes como "seus pressupostos filosóficos". No entanto esta solidariedade não é concebida como o reconhecimento de um eu profundo, a essência do homem, mas como a capacidade de julgar insignificante uma massa sempre maior de diferenças tradicionais (tribais, religiosas, raciais, de costumes etc.) em comparação com as semelhanças em relação à dor e a humilhação: a faculdade de englobar no campo do <nós> pessoas tão diferentes de nós (RORTY, 1989, p. 262-263; tradução nossa; grifo nosso).
}

Não pode haver moral se privilegiarmos os nossos em detrimento dos que não são nossos. Todos somos seres que sofremos com a dor e a humilhação. Resumindo o pensamento de Rorty:

Para os pragmatistas, o progresso moral poderia se acelerar se prestássemos atenção sobre
a aptidão que temos a minimizar as pequenas coisas que nos separam - não as
comparando à única coisa de real grandeza que nos une, mas comparando-as a outras
pequenas coisas. Para nós, pragmatistas, progredir moralmente, é antes de tudo costurar
um imenso tapete, policromo, em vez de procurar uma visão mais clara de algo mais claro
e mais profundo (RORTY, 1996, p. 125-126; tradução nossa).

Em Contingence, Ironie et Solidarité (1989) ele afirma que a solidariedade não pode ser concebida como um fato, mas sim como um objetivo a ser almejado e alcançado. Não se descobre 
a solidariedade pela reflexão, mas ela deve ser criada. "Esta criação tornando-nos mais sensíveis aos detalhes particulares da dor e da humilhação das pessoas que nos são pouco familiares" (RORTY, 1989, p. 17; tradução nossa), não apenas dos que são nossos parentes ou que nos são próximos. Portanto, concluímos que o "nós" não abrange os que denominamos nossos, mas um "nós" no qual incluímos a toda humanidade. Ou como escreve Jean-Paul Sartre (1970, p. 12), “a nossa responsabilidade é muito maior do que poderíamos supor, pois ela engaja a humanidade inteira".

Às extensas e densas explicações e considerações de Aristóteles (Ética a Nicômaco VI); de Tomás de Aquino (Suma Teológica II), para quem a lei natural é como princípio da razão prática; de Ludger Honnefelder (2010) e de outros que se ocuparam da questão, conferindo-lhe o fundo ético-metafísico ora negado, Rorty opõe estas definições:

[Dewey] via, na "prudência", um membro da mesma família dos conceitos de "hábito" e
"costume". Estas palavras descrevem as três maneiras habituais e relativamente
indiscutíveis que os indivíduos e os grupos têm de se ajustar às tensões e às restrições de
seu meio, humano e não humano. [...] "Prudência", "comodidade" e "eficácia" todos os
três termos descrevem estes ajustes às circunstâncias que são rotineiros e incontestáveis.
No caso contrário, moralidade e lei intervêm quando surge a controvérsia (RORTY, 1996,
p. 101-102; tradução nossa).

Do mesmo modo que não existe uma língua ou linguagem universal, assim também não existem obrigações universais. Por isso Dewey (1983) critica a ideia de universalizabilidade de Kant da seguinte maneira:

Kant em sua filosofia moral defendia "a doutrina segundo a qual a essência da razão reside numa universalidade integral (e, portanto, igualmente na necessidade e imutabilidade), com toda a seriedade condizente com um professor de lógica". O fato de Kant ter tentado procurar aconselhamento sobre o que fazer com a própria ideia de universalizabilidade representa menos, segundo a interpretação de Dewey, um impossível desprezo das consequências que uma simples "ampla visão imparcial das consequências" (DEWEY, 1983, p. 168). O que o imperativo categórico, segundo Dewey, faz é defender "o hábito de nos perguntar como desejaríamos nós próprios sermos tratados em caso similar". (DEWEY, 1983, p. 164 apud RORTY, 1995, p. 105).

Baseado nestes pressupostos, Rorty abriu o Fórum de Fontenoy, Paris, em 1996, de que trataremos a seguir.

Em vez de perguntar “Que somos nós”, é preciso perguntar “Quem somos nós”, sendo que "nós" aqui é considerado como um sujeito social e político.

"O que é o homem?". Ambas significam algo como "como é que a espécie humana difere do resto do reino animal?" ou quais as diferenças entre nós e os outros animais, que nos fazem melhores, com algo a mais (do que os animais possuem)? (RORTY, 1996, p. 314; tradução nossa).

Do conceito jurídico e moral segundo o qual a pessoa é responsável por seus atos, sui juris, a corrente cristã inferiu que a moral se aplica para todos os homens. Em outros termos, a moral é universal.

O universalismo moral tradicional combina uma resposta para a pergunta científica ou metafísica "o quê?" com uma resposta para a pergunta política "quem?". O universalismo pressupõe que a descoberta de traços compartilhados por todos os seres humanos é suficiente para mostrar o porquê, e talvez, como todos os seres humanos devem se 
organizar em uma Cosmópolis? (RORTY, 1989, p. 56; tradução nossa).

Na concepção rortyana (1989) a universalidade pressupõe que haja características partilhadas por todos os seres humanos, que formam uma comunidade humana ideal na qual todos seriam tratados com igualdade no sentido democrático, a saber respeitando-se as diferenças ${ }^{7}$.

\section{O que pode levar o rico a ser solidário, sobretudo com os menos favorecidos, segundo Rorty}

Rorty aponta formas de viabilizar o respeito pelas diferenças. Tais formas poderiam despertar nos mais ricos a solidariedade em relação aos mais pobres, em especial em relação àqueles que se encontram em extrema vulnerabilidade. Essas propostas são favoráveis à de igualdade democrática e, por esse motivo, elas serão elencadas a seguir.

\section{$1^{\circ}$. A sensibilidade}

Homo sum et nihil quod humanum est a me alienum puto. Sou homem, e nada do que é humano me é alheio.

(Terêncio)

O homem não é razão apenas. O homem é paixão. E é pela paixão que é levado a agir. Esta tese é defendida desde os filósofos antigos. Aristóteles, por exemplo, apresenta o homem como composto de corpo e alma, sendo a alma formada por uma parte racional que deve dominar, mas também por uma parte irracional responsável por inevitáveis desejos e paixões (Ética a Nicômaco I, 13; VI 1-2). Teorias semelhantes aparecem ainda em pensadores modernos e contemporâneos. Assim, a sensibilidade vai à simpatia e à compaixão: duas virtudes estudadas por André ComteSponville (1997). A palavra simpathia é oriunda da união da preposição grega sŷn = junto com o verbo patheîn = sofrer, significando, literalmente, sofrer junto com o outro. Trata-se de sentir com o outro. Max Scheller (1957) estabelece sua moral na simpatia. Ladriere (2004) afirma que a esperança da razão existirá quando se abrir à misericórdia. Martha Nussbaum $(2008 ; 2015)$ afirma que uma sociedade, para ser e se manter em estado de democracia liberal, deve ser compassiva, e para isso ressalta a necessidade de se formar cidadãos cuja compaixão e empatia os agrupem num sentimento de humanidade, embora haja peculiaridades em cada um.

Todavia, o homem contemporâneo procura não ver as dores do outro, procura não ver as diferenças. Racionaliza a pobreza: os pobres são preguiçosos, não são trabalhadores. Se trabalhassem poderiam procurar seu lugar ao sol. Esquecem que não possuem condições de estudos, que são analfabetos, que nasceram de pais em condição de fragilidade socioeconômica (se têm família), que não possuem teto. São abandonados pelo próprio Estado, que acha que 150 reais são suficientes para passar um mês.

Diante de tantas e evidentes disparidades percebidas, mas que podem não sensibilizar quanto aos problemas dos outros, Rorty afirma que, por despertarem a sensibilidade, muito podem ajudar a leitura de romances e os filmes. Para isso cita os efeitos da leitura da Cabana do Pai Tomás nos Estados Unidos que mitigou, em parte, as tendências racistas. Argumentos racionais não convencem ninguém, pois o homem não se motiva por lógica, pela razão, mas como

\footnotetext{
${ }^{7}$ Uma teórica política que defende algo semelhante e com uma reflexão aguda que vale ser lida é Hannah Arendt. Ela propõe que pela linguagem e pela ação os seres humanos se tornam parte de uma pluralidade, mas tal pluralidade ao mesmo tempo conserva as individualidades (cf. AREDNT, 2020).
} 
diz o vulgo, o homem age movido pelo coração, embora muitos tenham uma carcaça de aço que os torna impermeáveis aos sentimentos de paixão e de misericórdia.

\section{$2^{\circ} . \quad$ Mostrar o risco da pobreza para o rico}

Paira uma ameaça sobre o rico. Em primeiro lugar, precisa dar vazão ao consumo, ao transporte, às comunicações, aos bens, a todos os bens. Uma comunidade que se fecha em si mesma está fadada à ruína. Aliás, o rico fica sensível à distribuição da propriedade quando se sente ameaçado pelas invasões. Não que isto justifique qualquer invasão.

Para Posner a situação das subclasses dos marginalizados constitui "uma situação patológica" e não tem solução viável. Não é o que Rorty pensa. Sem dúvida, muitos ricos podem excluir os pobres de sua comunidade moral, considerando-os "como mortos" (RORTY, 1996, p. 9). Contudo, para se responder à pergunta: “quem somos nós?" de um modo que seja relevante para as questões morais, é preciso escolher a quem alguém está querendo fazer alguma coisa para ajudar. Segue-se que não é nem útil nem informativo responder a esta questão por preferência à classe de pessoas a quem não se tenha ideia de como ajudar. A identificação moral é vazia quando não existe vontade de hábitos e ação. É preciso que se leve em conta a questão monetária para que a ajuda ao subdesenvolvimento seja sustentável. Porque, após a redistribuição da riqueza, é mister que os ricos possam se reconhecer a eles mesmos, como aqueles que deverão estar aptos a isso.

O único modo no qual os ricos podem pensar de si mesmos como parte da mesma comunidade moral que os pobres é por referência a algum cenário em que haja esperança às crianças dos pobres sem privar seus próprios filhos da esperança. (RORTY, 1996, p. 9; tradução nossa).

\section{$3^{\circ}$. Apelo dos humanistas}

O mundo terá solução na medida em que os homens tiverem consciência da solidariedade. Karl Marx, citado por Erich Fromm (1969), ao responder à sua filha sobre qual teria sido a inspiração da obra e de sua vida revolucionária, afirmou que seguiu a inspiração de Terêncio, acima mencionada: interessar-se por todos os homens. E podemos dizer, de modo simples e inicial, que a solidariedade se caracteriza pelo fato de pensar e agir como membro da humanidade, sendo um com todos os homens.

Ser solidário é sentir-se ligado a todos os homens, não importando os interesses, fins e afinidades, sejam comuns ou não, mas buscando agir auxiliando-se mutuamente. Relembramos que Rorty, por sua vez, entende a solidariedade como a obrigação moral de agir "na intenção do nós", mas não um "nós" universal, posição imbuída do imperativo categórico de Kant (2005, p. 33). No entanto, para chegar à compreensão de que outros seres são iguais a nós, não o saberemos pela reflexão metafísica sobre a essência do homem, ou pelas conclusões lógicas. Para isso, precisase de algo mais empírico, mais próximo a nós, a saber, as descrições da etnografia, as reportagens, os filmes, o romance, a dramática documental e até de obras de ficção, por exemplo, as obras de Vladimir Nabokov (RORTY, 1994). Conforme as palavras do próprio filósofo:

Em minha utopia, a solidariedade seria percebida não como um fato de se ter consciência dissipando os "preconceitos" ou cavando até as profundezas ainda inexploradas, mas, antes, como um objeto a alcançar. E isto, não pela pesquisa, mas pela imaginação, a faculdade de reconhecer pela reflexão semelhanças que sofrem as pessoas que nos são estranhas. A solidariedade não se descobre pela reflexão, ela é criada. Ela é criada 
tornando-se mais sensível aos detalhes particulares da dor e da humilhação de outros tipos de pessoas que nos são pouco familiares. Com a ajuda desta sensibilidade aumentada, tornar-se-á mais difícil marginalizar pessoas diferentes de nós pensando: "Eles não sentem as coisas coma nós as sentiríamos", ou "Haverá sempre sofrimento, então por que não os deixar sofrer"? (RORTY, 1989, p. 17).

A solidariedade não é apenas formal, sem considerar o outro, seu rosto, seu olhar, que suplicam e que condenam ou que aprovam: o homem se esconde no anonimato, no "a gente" no "on" do francês, ou no "man" do alemão.

Para entender o que é agir por solidariedade é preciso examinar como agem as pessoas solidárias ${ }^{8}$. Pergunte-se aos dinamarqueses e aos milaneses por que ajudaram os judeus. Não dirão (talvez um ou outro dirá, por vício ideológico da repetição) que foi porque "eram seus semelhantes". Mas responderão porque: "aquela mulher é uma mãe igual à minha mãe"; "aquele homem era do meu sindicato e jogava futebol ou cartas comigo"; "aquelas outras pessoas são pais/mães de família e têm problemas iguais aos meus". Ao passo que aqueles que recusaram ajuda aos judeus, que não foram solidários, eram pessoas excluídas dos seus círculos de amizade e de semelhanças; ou, a proposição "ela é judia" era mais importante que "ela é mãe e tem filhos", "ela é uma estranha", enfim, segregada de "nós".

Da mesma maneira, não precisamos recordar a guerra para perceber como opera a

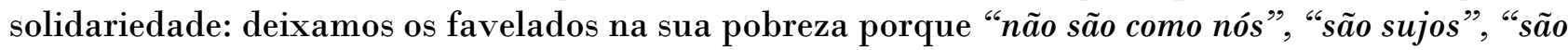
preguiçosos", "gostam da sujeira". Seríamos solidários e mais morais se os descrevêssemos como cidadãos brasileiros.

No entanto, esta solidariedade não é concebida como o reconhecimento de um eu profundo, a essência do homem, em todos os seres humanos, mas antes "como a capacidade de julgar insignificante uma massa sempre maior de diferenças tradicionais (tribais, religiosas, raciais, de costumes etc.) em comparação com as semelhanças que dizem respeito à dor e à humilhação: é a faculdade de englobar no campo do "nós "pessoas muito diferentes de nós". 9

\section{O igualitarismo de Rorty: Contingence, Ironie et Solidarité}

Há uma outra característica da solidariedade rortyana, e é uma das ideias centrais da obra Contingence, Ironie et Solidarité. Tal característica indica que não se necessita, para justificar a solidariedade, invocar "princípios primeiros"; a solidariedade é vista como uma obrigação, equivalendo a qualquer perspectiva que pretenda justificar de modo transcendental as obrigações morais. A proposição é feita porque Rorty é anti-metafísico e pleiteia uma "moral sem dogmas" (RORTY, 2009). Agir moralmente é agir em intenção do "nós".

A solidariedade tem origem histórica e parte das observações e considerações sobre a natureza do homem, mas como ser sensível à dor e à humilhação e que não é resultado de raciocínios lógicos. Notamos a diferença entre benevolência e as atitudes cruéis e percebemos seus efeitos sobre nós mesmos e sobre os outros, pois somos seres sensíveis e nos comovemos ao observar tais ações.

Este ponto de vista não se opõe, nem nega os avanços conseguidos pelo ponto de vista racional ou de outras posturas religiosas e ideológicas, segundo o ponto de vista do autor em tela ${ }^{10}$. Considerar a solidariedade como algo histórico é ver nisto um convite a alargar cada vez mais

\footnotetext{
${ }^{8}$ Proposta que de forma interessante se assemelha àquela de Aristóteles (EN II 4), ao afirmar que para ser virtuoso é preciso agir como agiria um homem virtuoso.

${ }^{9}$ Sobre este assunto, ver RORTY, 1989, p. 250-271

${ }^{10}$ Rorty não nega, como afirma o valor da perspectiva cristã ou kantiana, mas não é sobre elas que ele se fundamenta.
} 
nossos sentimentos de solidariedade: para com os membros de nossas famílias, para com os vizinhos, para com os do bairro, para aqueles da cidade; alargando, assim, cada vez mais o "nós", e fazendo o "ele" um "dos nossos". Não é procurar em nós um sentimento preexistente, nem um fundamento racional, mas termos a coragem de encarar o ele diferente como um dos nossos.

Não se trata de ver no nós uma "comunidade humana" com os "direitos naturais do homem", ou um "fundamento do regime democrático". Mas nós somos liberais do século XXI, que criamos instituições "sempre mais cosmopolitas" e cada vez mais democráticas. E a filosofia, nesse caso, não é um tribunal, mas um instrumento para recriar e tecer ideias com novo vocabulário, para atrair as pessoas para um diálogo no qual deve dominar o consenso. Com esse pressuposto poderemos acomodar novas crenças e distinguir a solidariedade humana da identificação com a humanidade como tal.

Não se pode duvidar da sensibilidade, própria e dos semelhantes, em relação à dor e à humilhação. É essencial que partilhemos do mesmo sentimento a respeito de qualquer sofrimento. E nesse aspecto não se pode distinguir as questões públicas das questões privadas. A mesma pessoa pode pertencer ao mesmo tempo aos dois domínios.

Por conseguinte, necessário se faz rejeitar o pressuposto de que a reflexão à base de nossas discussões tenha alguma filosofia pré-estabelecida ou um ponto de partida natural. Em nossa interpretação, para Richard Rorty mister se faz ser contingencialista, isto é, partir de circunstâncias históricas dadas. Não há nenhum princípio primeiro evidente como um fulcro ou âncora. Não há evidência primeira em moral. No caso das sociedades e do próprio eu não há uma essência de base, nem uma natureza comum como fundamento.

Se não se admite centro algum, há apenas modos diferentes. É, pois, pelo diálogo visando um consenso que se tecerá um modus vivendi numa sociedade melhor. A discussão e a persuasão devem se sobrepor a qualquer força política, sem jamais aceitar a coação pelo uso da violência ou de coações outras, psicológicas, morais, religiosas, econômicas ou ideológicas. A única política, nesse aspecto, que se possa aceitar é rejeitar a coação moral pelo uso da força, aceitando-se apenas a persuasão mediante diálogo e consenso.

O eu é construído, é um projeto que se realiza a partir das escolhas e das decisões individuais. Nesse caso, não se pergunta “o que sou eu?", mas “quem sou eu?". E a resposta é uma autocriação pelas próprias escolhas, sempre respeitando o espaço do outro, sua autonomia e liberdade, ou de acordo com Ulpiano: Neminem laedere, sui cuique tribuere, honeste vivere. ("Não ferir ou prejudicar quem quer que seja, dar a cada um o que lhe é devido, viver honestamente") ${ }^{11}$.

O sentimento de solidariedade, segundo Rorty, repousa sobre o sentimento de um perigo comum e não na partilha de uma força comum: esse sentimento comum é a suscetibilidade à humilhação, e o perigo comum é a ameaça da dor. É baseada, portanto, na justa vulnerabilidade à dor, e não numa identidade do público/privado. Não há como procurar um denominador comum a todos os homens que faria essa identidade.

Esse sentimento parece ser aquilo de que carece a sociedade atual. A percepção comum da possibilidade de dor e de humilhação causadas pela pandemia do Covid-19 ressalta a fragilidade humana e a necessidade cada vez maior da solidariedade. Aguçar a percepção de que é-se igualmente suscetível à contingência que aflige os mais fracos talvez seja o fator necessário à manutenção da vida em sociedade em tempos como estes. Tal percepção parece possível não somente por meio da racionalização e do entendimento metafísico de que existe uma humanidade comum, mas pelo cultivo de uma sensibilidade desenvolvida por meios educativos diferentes do

\footnotetext{
${ }^{11}$ A citação de Ulpiano que traduzimos encontra-se em: Juris civilis antejustinianei reliquiae in edite ex cod. rescr. bibliotheca\} vaticanae, ou Vaticana Fragmenta. Justinian, Digest 1.1.10, in Watson, Alan (ed.) (1985). The Digest of Justinian. Philadelphia: University of Pennsylvania Press.
} 
cálculo racional ou da imposição de dogmas.

\section{Conclusão}

Durante a pandemia vemos a necessidade de uma ética diferente da ética utilitarista egoísta que se sobressai atualmente. $\mathrm{O}$ destaque dado, especialmente pelas grandes potências e neste período específico, aos problemas econômicos os superpõe a questões humanistas e humanitárias mais urgentes. Isso desperta nossa atenção e reflexão acerca de um possível impasse quanto a uma ética cabível à atualidade. Mesmo após tentativas de revisão do utilitarismo, como aquela feita por Rawls, esse tipo de pensamento e comportamento parece ativo de uma forma distorcida e nociva. Sob o princípio do utilitarismo, especialmente como o percebemos hoje, oculta-se o fato de que as decisões humanas dependem muito dos centros hedonísticos do cérebro, sobre os quais o controle de tipo racional é difícil. Todavia, após serem iniciadas de forma voluntária, as ações passam a ser controladas conscientemente. Por isso, a hipótese de Rawls de uma legislação sob um "véu da ignorância" nos parece inviável. Assim como parecem inviáveis as propostas de um imperativo categórico, de uma intuição inata do bem na consciência humana, ou mesmo de um governante único que reja em nome de todos. Por isso foi necessário procurar por outro critério ético que atendesse a um "nós" não excludente.

Sendo assim, vemo-nos obrigados a reforçar a questão: qual ética para hoje? Pela crítica às éticas anteriores e àquela que percebemos como mais presente hoje em dia, vimos na teoria da solidariedade uma alternativa considerável. A solidariedade é aqui entendida como o que une os seres humanos a fim de que colaborem mutuamente, sendo oposta ao egoísmo e ao egocentrismo, fazendo frente à injustiça e levando a um sentimento comum de responsabilidade e de dependência. As pessoas se veem agrupadas pela existência comum ao menos de interesses, mas especialmente pela suscetibilidade à dor e à humilhação. Nesse sentido, entendemos que a solidariedade seja uma necessidade na sociedade 5.0, na qual observamos como crescentes as chances de existirem diferenças sociais, econômicas e de outros tipos, alargando o abismo entre ricos e pobres. Assim, concordamos com Rorty quando ele indica a necessidade de um acordo em prol de um "nós" que agregue os membros da sociedade. Também estamos de acordo com a premência da observação de princípios éticos, mas se as éticas supramencionadas e outras não atendem os problemas atuais é preciso uma alternativa como a que indicamos.

Como ironista liberal, Rorty abre-se à discussão de suas crenças e opiniões, além de não aceitar que se cause dor e humilhação a um ser humano. Não obstante, como pensador pragmatista autodeclarado (RORTY, 1995), pensa o universal moral pelo viés da prática da solidariedade e do auxílio prestado por pessoas em condições de praticá-la em direção aos que estão em condições adversas. Porém, indica a solidariedade não como um fato, mas como um objetivo ao qual se aspira e se busca realizar. Realizado, este objetivo nos tornaria mais atentos à dor e à humilhação alheia, sentida por aqueles que não nos são próximos ou conhecidos. Assim haveria uma possibilidade para existência daquele "nós" mais abrangente, que incluísse a todos.

No entanto, ao pensar um associador humano, diferente dos teóricos que privilegiam o aspecto metafísico dos princípios que norteiam o agir humano, Rorty não pergunta pelo ser humano com intenção de distinguir a essência dele, mas dá à indagação um tom social e político. Substitui a questão "o que somos nós?" por "quem somos nós?", portanto. Esse tipo de postura investigativa leva à versão universalista repensada pelo filósofo, conforme a qual todos os seres humanos partilham características relativas à sua fragilidade, e não por serem uma espécie animal diferente das demais, por exemplo. Idealmente, todos seriam tratados de forma igualitária democrática, com respeito às diferenças de cada um. 
Para a viabilização desse tipo de relação, o filósofo aponta três fatores igualitários: a sensibilidade, a apresentação aos ricos da possibilidade de pobreza e o apelo dos humanistas. Quanto à sensibilidade, a questão é compreender que o ser humano é, além de racional, passional. Sendo compelido a agir pela paixão, seria inegável que ela estivesse presente na vida em sociedade. Porém, o homem contemporâneo parece buscar racionalizar os infortúnios e as dificuldades que acometem outros seres humanos, tomando certa distância deles. Assim, deixa-se insensível às diferenças e aos problemas que não considera seus, contrariando a proposta rortyana segundo a qual despertar a sensibilidade motivaria a ação solidária. Para tal motivação, o filósofo sugere que as artes são auxiliares eficazes.

As artes poderiam também favorecer a igualdade democrática ao mostrar aos ricos o risco da pobreza ${ }^{12}$, despertando sua imaginação. Se eles fossem capazes ao menos de imaginar uma situação de vulnerabilidade econômica e social, seria possível uma identificação moral. Se ao menos imaginassem que é possível às crianças pobres mudarem sua condição desfavorecida sem prejuízo aos filhos deles, talvez se abrissem à solidariedade e, consequentemente, a uma associação humana que favorecesse o verdadeiro "nós".

Desse modo, entendemos que é preciso despertar, seja com auxílio das artes, seja por outros meios, a solidariedade, saída para a qual apelam os humanistas. Esta, em suma, resulta de agir e pensar como um membro da comunidade humana, da percepção de algo comum que associa os seres humanos: a possibilidade de dor e humilhação que leva à colaboração mútua, como sinalizamos. Reforçamos que a solidariedade é, na "utopia" de Rorty (1989, p. 17), entendida como um projeto, como algo a ser alcançado, e não como algo já existente. Facultada pela imaginação que leva a reconhecer o sofrimento alheio, mas que pode acontecer a qualquer um. A solidariedade torna-se uma ampliação da sensibilidade e dificulta que se ignore o infortúnio do outro. Portanto, não é constituída por um entendimento de que somos metafisicamente iguais. Sendo assim, conforme Rorty, ela levaria à ação que intenta àquilo que é benéfico ao "nós", associaria nesse "nós" pessoas que poderiam ser consideradas muito diferentes para pertencerem a um mesmo grupo.

Portanto, a proposta ética rortyana da solidariedade nos soa como plausível para o hoje, pois entende agir moralmente como agir na intenção do "nós". O fato de os humanos serem suscetíveis à dor e à humilhação, independente de formulações racionais, é que permitiria tal elo. Entender-nos como vulneráveis nos tornaria capazes de nos comover com o infortúnio alheio, de imaginá-lo, por mais que cada membro de tal "nós" seja peculiar. Isso talvez cedesse espaço para o diálogo, para a reflexão, à medida que se percebesse uma humanidade ao mesmo tempo distinta e unificante em cada um. $O$ que seria possível não com apoio em uma compreensão de que existe algo natural, essencial a todos os seres humanos, mas pautada em questões históricas, contingenciais, devidas à vulnerabilidade comum. A procura por um consenso em prol dos mais desfavorecidos acolhidos nessa humanidade seria uma lição bem-vinda nestes tempos de pandemia.

\footnotetext{
12 A aposta no poder de despertar a sensibilização por meio da imaginação provocada pelas artes e pelas humanidades é trazida para nós no manifesto Sem fins lucrativos de Martha C. Nussbaum (2015).
} 


\section{Referências}

AgOSTINHO. Solilóquios; A vida feliz. São Paulo: Paulus, 2007. (Coleção Patrística)

ARENDT, Hannah. A condição humana. Brasília: Forense Universitária, 2020.

ARISTÓTELES. Ética a Nicômaco. In: Aristóteles. São Paulo: Abril Cultural, 1973. v. 2. (Os pensadores)

CÍCERO, Marco Túlio. De Officis. London; New York: Loeb Classical Library, 1913.

COMTE-SPONVILLE, André. Pequeno Tratado das Grandes Virtudes. São Paulo: Martins Fontes, 1997.

DEWEY, John. Human Nature and Conduct. In: The Middle Works of John Dewey. Cabondale, Illinois, Southern Illinois: University Press, 1993. v. 14.

FROMM, Erich. Conceito Marxista de Homem. Rio de Janeiro: Zahar, 1969.

GLADDEN, Matthew E. Who Will Be the Members of Society 5.0? Towards an Anthropology of Technologically Posthumanized Future Societies. Soc. Sci. 2019, 8, 148. Disponível em: https://www.mdpi.com/journal/socsci. Acesso em: 28 jul. 2020.

HOBBES, Thomas. Leviatã ou matéria, forma e poder de uma república eclesiástica e civil. São Paulo: Martins Fontes, 2003.

HONNEFELDER, Ludger. A lei natural de Tomás de Aquino como princípio da razão prática e a segunda escolástica. Teocomunicação. Porto Alegre, v. 40, n. 3, p. 324-337, set./dez. 2010. Disponível em: https://revistaseletronicas.pucrs.br/ojs/index.php/teo/article/view/8155/5842. Acesso em: 01 fev. 2021.

HOTTOIS, Gilbert. De la renaissance à la postmodernité. Une historie de la philosophia moderne contemporaine. Paris; Bruxelles: De Boeck et Larcier, 1997.

KANT, Immanuel. Fundamentação da Metafísica dos Costumes. Lisboa: Edições 70, 2005.

LADRIERE, Jean. L'espérance de la raison. Louvain-Paris: Editions Peeters, 2004.

LA CRISE du Covid-19 requiert une solidarité mondiale sans précédent.

Le Monde, Paris, 14 abr. 2020. Disponível em:

https://www.lemonde.fr/idees/article/2020/04/14/la-crise-du-covid-19-requiert-une-solidarite-

mondiale-sans-precedent_6036561_3232.html. Acesso em: 14 abr. 2021.

NUSSBAUM, Martha Craven. Upheavals of thought: The Intellegence of Emotions. Cambridge: Cambridge University Press, 2008.

NUSSBAUM, Martha Craven. Sem fins lucrativos: Por que a democracia precisa das humanidades. São Paulo: Martins Fontes, 2015.

OVÍDIO. Metamorfoses. São Paulo: Editora 34, 2017.

PÚBLIO OVÍDIO NASO. Les Metamorphoses. Paris: Gallimard, 1992.

PARMET, Wendy E. Populations, Public Health, and the Law. Washington, D.C.: Georgetown University Press, 2008.

PINKER, Steven. O novo iluminismo. Em defesa da razão, da razão e do iluminismo. 3. ed. São Paulo: Companhia das Letras, 2018.

PUBLIUS TERENTIUS AFER. Heaautontimorumenos. New York: Charles Scribner's, 1985.

Disponível em: rchive.org/stream/selftormentorhea00rico/selftormentorhea00rico_djvu.txt. Acesso em: 20 fev. 2021.

RAWLS, John. Teoria da Justiça. Brasília: Editora UNB,1981.

RONDEL, David. Pragmatist Egalitarianism. Oxford: Oxford University Press, 2017.

RORTY, Richard. Contigence, Ironie \& Solidarité. Paris: Armand Colin, 1989.

RORTY, Richard. Contingência, ironia e solidariedade. Lisboa: Presença, 1994.

RORTY, Richard. Por uma moral sem dogmas. Curitiba: Juruá, 2009. 
RORTY, Richard. Une éthique sans obligations universelle in L'espoir au lieu du savoir. Une Introduction au pragmatismo. Paris: Albin Michel, 1992.

RORTY, Richard. Who are we? Moral Universalism and Economic Triage. Diogenes. 44:173 (spring 1996): 5-15. Diponível em: http://www.kyoolee.net/Who_Are_We__Moral_Universalism_and_Economic_Triage_-_Richard_Rorty.pdf. Acesso em: 09 mai. 2021. SARTRE, Jean-Paul. O Existencialismo é um Humanismo. Paris: Les Éditions Nagel, 1970. SCHELER, Max. Esencia y Formas de la Simpatia. Buenos Aires, Losada, 1957.

STEELE, Richard. In.: The Spectator. London: George Rutledge and Sons, Limited, 1891. v. 3. Disponível em: https://www.gutenberg.org/files/12030/12030h/SV3/Spectator3.html\#section502. Acesso em: 21 fev. 2021.

SUMPTER, David. Dominados pelos números: Do Facebook e Google às fake news - Os algoritmos que controlam nossa vida. Rio de Janeiro: Bertrand Brasil, 2019.

TOMÁS DE AQUINO. Suma Teológica. Porto Alegre: Sulina, 1980. v. 2.

ULPIANO. In.: JUSTINIAN. The Digest of Justinian. Philadelphia: University of Pennsylvania Press, 1985.

WILSON, Edward Osborne. A Unidade do Conheimento-Consiliência. Rio de Janeiro: Campus, 1998.

Contribuição dos(as) autores(as) / Author's Contributions: Alvino Moser é o principal autor deste artigo, sendo seu idealizador. Dedicou-se aos trabalhos de pesquisa e propôs a estrutura central do texto; além disso, redigiu e atuou na revisão do trabalho. José Lauro Martins é coautor do artigo. Colaborou com a pesquisa e a redação, bem como com a revisão do texto. Juliana Santana também é coautora do artigo. Colaborou com os trabalhos de pesquisa, redação e revisão efetuados e que resultaram no artigo ora publicado. Os(As) autores(as) aceitaram e aprovaram a versão final do texto.

Autor(a) para correspondência / Corresponding author: Alvino Moser. moseral.am@gmail.com 